\title{
Comparative Infectivity of Cronartium ribicola Aeciospores and Urediniospores in Genotypes of Ribes nigrum
}

\author{
D. T. Dalton, Oregon State University, Department of Horticulture, Corvallis 97331; and J. D. Postman and \\ K. E. Hummer, U.S. Department of Agriculture, Agricultural Research Service, National Clonal Germplasm Re- \\ pository, Corvallis, OR 97333-2521
}

\begin{abstract}
Dalton, D. T., Postman, J. D., and Hummer, K. E. 2010. Comparative infectivity of Cronartium ribicola aeciospores and urediniospores in genotypes of Ribes nigrum. Plant Dis. 94:461-464.

Hosts for the fungus Cronartium ribicola, causal agent of white pine blister rust (WPBR), include five-needle pines as aecial hosts, and currants and gooseberries as uredinial/telial hosts. Aeciospores produced on diseased pine, and urediniospores produced on diseased Ribes plants, can infect Ribes foliage. Resistance and susceptibility for both spore types have been reported for Ribes; however, the comparative infectivity of these spore types on clonal Ribes nigrum genotypes is under-described. Immunity, resistance, and susceptibility to WPBR resides at a clonal level in Ribes. Previous studies have emphasized fungal diversity or forestry considerations, rather than horticultural aspects. The objective of this study was to determine if aeciospores and urediniospores were equally infective to specific genotypes of black currant, Ribes nigrum, with differential responses. A family of 51 black currant genotypes from a cross between a known-immune cultivar containing the $\mathrm{Cr}$ gene and a susceptible cultivar was examined. Single-leaf softwood cuttings of each of these genotypes were artificially inoculated with a spore solution and incubated in airtight plastic containers within a growth chamber. Inoculations were replicated three times for each spore type. Twenty-two of the $\mathrm{F}_{1}$ genotypes did not develop uredia after artificial inoculation. These may be immune; 22 developed uredia after exposure to both types of inoculum, and were susceptible; whereas seven exhibited differential responses and may have some mechanism for resistance to WPBR other than the $\mathrm{Cr}$ gene. The infectivity of aeciospores and urediniospores was not significantly different on specific Ribes genotypes. Either spore type can therefore be considered equally effective as inoculum when screening for WPBR resistance or immunity in horticultural settings.
\end{abstract}

The fungal pathogen Cronartium ribicola J.C. Fischer, causal agent of white pine blister rust (WPBR), was introduced to the eastern United States about 1898 (11). Hosts for the fungus include fiveneedle pines (Pinus sp. section Quinquefoliae) and currants and gooseberries (Ribes sp.). Natural infection of wild populations of Pedicularis bracteosa Benth and Castilleja Mutis ex L.f. have also been documented, although these two genera are considered minor hosts of the disease $(14,20)$. The damaging effects of WPBR on host white pines diminished the appeal of Ribes cultivation in the United States for most of the twentieth century; however, Ribes crops have been a mainstay of the small fruit industry in Europe for decades (1). The fungus produces pycnia and aecia on five-needle pines, and uredinia, telia, and basidia on Ribes $(13,15)$. Aeciospores,

Corresponding author: K. E. Hummer

E-mail: Kim.Hummer@ars.usda.gov

Accepted for publication 21 December 2009.

doi:10.1094/PDIS-94-4-0461

This article is in the public domain and not copyrightable. It may be freely reprinted with customary crediting of the source. The American Phytopathological Society, 2010. produced from cankers on diseased pines, and urediniospores, originating from uredinia on abaxial leaf surfaces of susceptible Ribes, can infect Ribes foliage. Susceptible Ribes may be defoliated by $C$. ribicola where infection incidence is high (3). Pine hosts can be killed by WPBR stem canker infections. Resistance to WPBR has been identified through the action of dominant genetic inheritance in aecial hosts $(11,12)$ and telial hosts $(1,2,4-8,16)$. Although Richardson et al. (16) have reported infection in Ribes nigrum L. by both spore types, they did not report the response of different spore types at the Ribes clonal level. Differential infectivity of these spore types could change breeding strategies for developing new Ribes cultivars resistant to WPBR. Previous horticultural studies have examined Ribes susceptibility to urediniospores (7-9). An unanswered question is: do aeciospores and urediniospores infect Ribes genotypes equally? The objective of this study was to determine whether both spore types were infective to a set of $F_{1}$ genotypes of $R$. nigrum with known diverse WPBR response.

\section{MATERIALS AND METHODS}

Plant materials. A study was initiated in 2007 at the U.S. Department of Agriculture, Agricultural Research Service, Na- tional Clonal Germplasm Repository (NCGR) in Corvallis, OR. $\mathrm{F}_{1}$ genotypes of $R$. nigrum 'Ben Lomond' $\times$ 'Consort' were chosen for this study. Consort contains the $\mathrm{Cr}$ gene for WPBR immunity, and uredia do not form on this plant. Because this gene is inherited as a simple dominant trait (4), half of its $F_{1}$ genotypes should also be immune, and half susceptible.

Hardwood cuttings from dormant, fieldgrown $\mathrm{F}_{1}$ seedlings of $R$. nigrum 'Ben Lomond' $x$ 'Consort' were rooted in the greenhouse. The rooted cuttings were transferred into 3.78-liter (1 gal) containers in the early summer and maintained outdoors. Additional clonal material was propagated by softwood cuttings in July 2007 and remained inside the greenhouse for the duration of the study. $R$. nigrum 'Seabrook's Black' (PI 556176) served as the WPBR-susceptible control (7), and 'Coronet' (PI 617906) was the resistant control (6).

Spore collection and storage. Aeciospores were collected from three Oregon populations of $C$. ribicola. Spores were collected from mature aecia with a handheld aspirator on 12 March 2008 at the USDA, Umpqua National Forest, Dorena Genetic Resource Center (DGRC) near Cottage Grove, OR. Aeciospores from $C$. ribicola strain OR07.01 were collected on 4 June 1995 at Miller Lake, Winema National Forest, Klamath County, OR and cryogenically preserved at $-80^{\circ} \mathrm{C}$ (P. J. Zambino, personal communication). Aeciospores from a third population of C. ribicola were sampled on 12 July 2008 near Tombstone Pass (TP), Willamette National Forest, Linn County, OR. The DGRC aeciospores were stored at $4^{\circ} \mathrm{C}$ until early summer, and both of the other aeciospore sources were maintained at $-20^{\circ} \mathrm{C}$ for the duration of the study. Aeciospores were assayed on $2 \%$ agarose plates for viability.

Urediniospores were harvested from heavily infected Ribes leaves. The first urediniospore inoculation trial used field inoculum from the NCGR. To increase the late-season urediniospore inoculum, susceptible $R$. nigrum 'Baldwin,' 'Bogatyr,' and 'Minaj Shmyrev,' and $R$. malvaceum Sm. 'Wunderlich' were inoculated with TP aeciospores on 8 August and 2 September 2008. Multiple sources of spores were used so that sufficient inoculum could be obtained. 
Growth chamber inoculations. To produce aeciospore-water-agarose solution, dry aeciospores were added to sterile water-agarose solution ( $0.07 \%$ concentration) at a rate of $250 \mathrm{mg} 1,000 \mathrm{ml}^{-1}$ and dispersed evenly in solution. A Neubauer hemacytometer (Hausser Scientific Partnership, Horsham, PA) was used to determine spore concentration. The aeciosporewater-agarose solution contained approximately $5 \times 10^{4}$ spores $\mathrm{ml}^{-1}$. The spore solution was poured into a sterile mist bottle to facilitate spray inoculation of the softwood cuttings.

Urediniospores were collected by scraping uredinial pustules of infected Ribes leaves with the plastic tip of a disposable transfer pipette (VWR Scientific, Inc., San Francisco, CA) to dislodge mature spores. Sterile water-agarose solution was then pipetted over the leaf surface to wash the spores into a beaker. The spore density of the resulting urediniospore-water-agarose solution was determined and diluted with sterile water-agarose solution to approximately $5 \times 10^{4}$ spores $\mathrm{ml}^{-1}$. Urediniosporewater-agarose solution was limited, due to unavailability of additional spores, and was dabbed onto the abaxial leaf surfaces with the aid of a disposable transfer pipette.

Aeciospore and urediniospore treatments uniformly covered the leaf surfaces

Table 1. Ribes nigrum $\mathrm{F}_{1}$ genotype susceptibility following inoculation in 2008 with aeciospores and urediniospores of Cronartium ribicola

\begin{tabular}{|c|c|c|c|}
\hline Genotype & Status $^{\mathrm{a}}$ & $\begin{array}{l}\text { Aeciospore } \\
\text { no. infected }\end{array}$ & $\begin{array}{l}\text { Urediniospore } \\
\text { no. infected }\end{array}$ \\
\hline 001 & $r$ & 0 & 0 \\
\hline 002 & $\mathrm{~s}$ & 2 & 1 \\
\hline 003 & $r$ & 0 & 0 \\
\hline 005 & $\mathrm{~s}$ & 3 & 1 \\
\hline 006 & $\mathrm{r}$ & 0 & 0 \\
\hline $007^{\mathrm{b}}$ & $\mathrm{s}$ & 0 & 1 \\
\hline 008 & $\mathrm{~s}$ & 2 & 4 \\
\hline 009 & $\mathrm{~s}$ & 3 & 1 \\
\hline 010 & $\mathrm{~s}$ & 1 & 3 \\
\hline 011 & $r$ & 0 & 0 \\
\hline $013^{b}$ & $\mathrm{~s}$ & 0 & 1 \\
\hline $014^{b}$ & $\mathrm{~s}$ & 1 & 0 \\
\hline 015 & $\mathrm{~s}$ & 1 & 2 \\
\hline 016 & $\mathrm{r}$ & 0 & 0 \\
\hline $023^{b}$ & $\mathrm{~s}$ & 0 & 3 \\
\hline $025^{\mathrm{b}}$ & $\mathrm{s}$ & 1 & 0 \\
\hline 027 & $\mathrm{~s}$ & 2 & 1 \\
\hline 029 & $\mathrm{~s}$ & 2 & 1 \\
\hline 031 & $\mathrm{~s}$ & 3 & 3 \\
\hline 032 & $\mathrm{~s}$ & 1 & 1 \\
\hline $033^{b}$ & $\mathrm{~s}$ & 0 & 2 \\
\hline 037 & $\mathrm{~s}$ & 1 & 3 \\
\hline 041 & $\mathrm{r}$ & 0 & 0 \\
\hline 042 & $r$ & 0 & 0 \\
\hline 043 & $\mathrm{r}$ & 0 & 0 \\
\hline 045 & $\mathrm{r}$ & 0 & 0 \\
\hline 047 & $\mathrm{r}$ & 0 & 0 \\
\hline 048 & $\mathrm{~s}$ & 2 & 2 \\
\hline 049 & $\mathrm{~s}$ & 1 & 3 \\
\hline $050^{\mathrm{b}}$ & $\mathrm{s}$ & 0 & 1 \\
\hline 053 & $\mathrm{~s}$ & 2 & 2 \\
\hline 057 & $\mathrm{r}$ & 0 & 0 \\
\hline 065 & $\mathrm{~s}$ & 1 & 1 \\
\hline 066 & $r$ & 0 & 0 \\
\hline 069 & $\mathrm{r}$ & 0 & 0 \\
\hline 073 & $\mathrm{~s}$ & 3 & 2 \\
\hline 074 & $\mathrm{~s}$ & 1 & 2 \\
\hline 076 & $\mathrm{~s}$ & 3 & 3 \\
\hline 081 & $\mathrm{~s}$ & 2 & 1 \\
\hline 082 & $\mathrm{~s}$ & 2 & 1 \\
\hline 085 & $\mathrm{r}$ & 0 & 0 \\
\hline 096 & $\mathrm{r}$ & 0 & 0 \\
\hline 097 & $\mathrm{~s}$ & 2 & 1 \\
\hline 101 & $\mathrm{r}$ & 0 & 0 \\
\hline 103 & $r$ & 0 & 0 \\
\hline 106 & $\mathrm{r}$ & 0 & 0 \\
\hline 107 & $\mathrm{r}$ & 0 & 0 \\
\hline 114 & $\mathrm{~s}$ & 2 & 3 \\
\hline 115 & $\mathrm{r}$ & 0 & 0 \\
\hline 116 & $r$ & 0 & 0 \\
\hline 117 & $\mathrm{r}$ & 0 & 0 \\
\hline
\end{tabular}

${ }^{\text {a }}$ Status: $\mathrm{r}=$ resistant; $\mathrm{s}=$ susceptible.

b Differentially infected genotypes.

nearly to the point of runoff. Spore solution was agitated periodically during inoculation to ensure uniform distribution of spores in suspension. Leaves were calculated to receive a mean 542 spores $\mathrm{cm}^{-2}$ for spray inoculation with aeciospores and 703 spores $\mathrm{cm}^{-2}$ for dab inoculation with urediniospores.

Inoculation chambers were modified from Zambino (19). The experiment was 2-way factorial design with interaction; spore type and genotype were the main effects; with three replicates. Limited growth chamber space precluded treatment of all genotypes on a single date, although three replicates of each genotype received applications of each spore type in separate trials. Aeciospore inoculation treatments were applied in 2008 on 27 March, 9 June, 6 August, and 14 October. Urediniospore treatments were applied on 13 August, 31 August, 8 September, 16 September, 27 September, and 6 October. Urediniospores were used fresh from heavily infected leaves as needed, except for the last date, on which the remaining urediniospore solution from the previous date was used. This spore solution was re-assayed to confirm viability at the time of inoculation.

Inoculation trials utilized unrooted softwood cuttings from the $\mathrm{F}_{1}$ genotypes (14). Clones were watered and fertilized 24 to $48 \mathrm{~h}$ prior to inoculation and placed in a staging area to allow the leaves to dry. On inoculation day, a cutting was taken from each clone and stripped of all but the youngest fully expanded leaf. The abaxial surface of the leaf was treated with spore solution. Following treatment, the plantlet was immediately set into moist, sterile vermiculite inside an individual airtight polypropylene inoculation chamber. To provide humidity, the upper segment of the inoculation chamber was misted with $\mathrm{dH}_{2} \mathrm{O}$ just prior to sealing the plantlet inside. Only one spore type was used per inoculation date.

Treated plantlets were incubated inside an illuminated growth chamber programmed to provide a 16-h photoperiod on a diurnal cycle. Aeciospore treatments remained within the growth chamber at $16^{\circ} \mathrm{C}$ for 3 days following treatment, after which the temperature was increased to $20^{\circ} \mathrm{C}$ (19). Urediniospore treatments were maintained at $20^{\circ} \mathrm{C}$ for the entire period within the growth chamber. These temperatures are within the optimal temperature range for spore germination and infection $(10,15)$. The plastic lids of the inoculation chambers were replaced with tissue paper after 3 days to allow the interior surfaces to dry. These techniques discouraged secondary infection, promoted adventitious rooting of the cuttings inside the cells of vermiculite, and provided an environment favorable for spore germination and disease development. To make space for subsequent inoculation trials, inoculation chambers were removed from 
the growth chamber after 1 week and placed into large, clear plastic bins (Tupperware Corporation, Orlando, FL) under ambient room temperature and diffuse light. The inoculated leaves were examined weekly with a magnifying lamp for signs of $C$. ribicola. If no infection was present, plantlets received a score of 0 , and if uredinial colonies were visible, plantlets received a score of 1 .

Due to space limitations and contamination of the rooted cuttings with powdery mildew (Podosphaera mors-uvae (Schwein) U. Braun \& S. Takam.), no single inoculation procedure screened all $\mathrm{F}_{1}$ genotypes concurrently. However, each of the $51 \mathrm{~F}_{1}$ genotypes received three treatments with each spore type. To control powdery mildew in the greenhouse, piperalin (Pipron liquid concentrate) was applied in spring 2008 according to label instructions. Once powdery mildew had been eradicated, elemental sulfur was vaporized nightly to create an unfavorable environment for spread of powdery mildew. The climatecontrolled growth chamber had insufficient capacity to hold all representative genotypes at once, and each set of experimental units required at least 1 week within the growth chamber before being transferred to the large plastic bins. Given these limitations, a random number generator selected suitable clones for each inoculation date from the available greenhouse-grown, non-WPBR-infected plants.

Statistics. A two-factor analysis of variance (ANOVA) model was evaluated using the S+ statistical package (Insightful Corporation, Seattle, WA) to determine the significance of spore type and $\mathrm{F}_{1}$ genotype, and their interaction, for susceptibility. In addition, homogeneity chi-square analysis was conducted, with the null hypothesis assigned that the aeciospore and urediniospore results would be homogeneous (17). Because the expected numbers of susceptible and resistant genotypes were greater than 20, the Yates correction factor was not used in chi-square analysis (17).

\section{RESULTS}

Control genotypes Seabrook's Black (susceptible) and Coronet (immune) were not included in statistical analyses of genetic resistance in the $\mathrm{F}_{1}$ population. Coronet was asymptomatic throughout the study.

In the greenhouse, a total of 357 singleleaf plantlets, representing 51 distinct $F_{1}$ genotypes, were inoculated during the 2008 growing season (Table 1). Of the plantlets, $92(25.8 \%)$ developed $C$. ribicola uredia, representing 29 of the 51 genotypes. The proportion of greenhouseinfected genotypes supported the expected 1:1 segregation ratio of the $C r$ gene $\left(\chi^{2}=\right.$ $0.48, \mathrm{df}=1, P=0.49$ ) (Table 2).

The $F_{1}$ population did not deviate from the expected 1:1 ratio of resistance to $C$. ribicola. Artificial inoculation with uredin- iospores caused infection on 27 of the 51 genotypes $\left(\chi^{2}=0.088\right.$, df $\left.=1, P=0.767\right)$. The pooled results (51 infected, 51 uninfected) yielded a chi-square value matching the expected $1: 1$ ratio $\left(\chi^{2}=0, \mathrm{df}=1, P\right.$ $=0.999)$. A chi-square test of homogeneity showed that aeciospore and urediniospore inoculations produced disease on a similar number of genotypes $\left(\chi^{2}=0.157, \mathrm{df}=1, P\right.$ $=0.692)$ (Table 2).

Of the $51 \mathrm{~F}_{1}$ genotypes, 22 showed susceptibility to both aeciospores and urediniospores in the growth chamber, and 22 were resistant to both treatments. Two genotypes were susceptible only to aeciospores, whereas five appeared susceptible only to urediniospores (Table 3). A twofactor ANOVA demonstrated a significant effect of genotype $(P<0.001)$ but a nonsignificant effect of spore type $(P=0.291)$ on susceptibility, and the interaction of genotype by spore type was not significant (Table 4).

\section{DISCUSSION}

Aeciospores and urediniospores of $C$. ribicola are equally able to cause disease on Ribes genotypes. In addition, the genotype $\times$ sporetype interaction was not significant, indicating that phenotypic responses to WPBR were consistent; aeciospore and urediniospore treatments produced disease on the same genotypes. Despite these findings, 7 of the 51 genotypes showed differential disease responses to C. ribicola spore type (Tables 1 and 3). For these genotypes, urediniospores revealed five susceptible plant genotypes not detected by aeciospores, and aeciospores revealed two susceptible genotypes not detected by urediniospores.

In $R$. nigrum, the $C r$ gene is inherited in a simple dominant pattern (4). This study produced no evidence that separate genetic mechanisms control resistance and susceptibility in $F_{1}$ genotypes. Rather, certain genotypes escaped infection by one or both spore types.

Our findings go beyond that of Richardson and colleagues (16), who observed aeciospore or urediniospore infectivity during inoculation experiments within Pedicularis and Ribes populations. They did not examine multiple inoculations of specific clones, as we did. Because of the equivalent qualitative infection outcome of both aeciospores and urediniospores, these data indicate that either spore type can be applied to Ribes foliage during artificial greenhouse inoculation trials or for disease assessment in areas where WPBR is naturally absent or occurs sporadically. Nonetheless, in forest settings, Ribes may produce more uredinia when challenged with aeciospores as compared to urediniospores. This is likely due to timing of leaf emergence and aeciospore hardiness. Aeciospores can survive in the jet stream and travel $500 \mathrm{~km}$ (18); urediniospores are less tolerant of extreme conditions (15). Young leaf tissue is more susceptible to infection by $C$. ribicola than is old, hardened, or sun-exposed material $(15,19)$. Leaf age may therefore play a significant role in spore infectivity. Variations in topography and microclimatic effects cause variation of aeciospore production. These factors allow aeciospores to be shed nearly yearround (15), thereby extending the time

Table 2. Disease response of 51 Ribes nigrum $\mathrm{F}_{1}$ genotypes to Cronartium ribicola aeciospore and urediniospore treatments with chi-square values

\begin{tabular}{lcccccc}
\hline Treatment & Susceptible & Resistant & Exp. ratio & \multicolumn{1}{c}{$\boldsymbol{\chi}^{\mathbf{2}}$} & $\boldsymbol{P}$ & df \\
\hline Total & 29 & 22 & $1: 1$ & 0.48 & 0.49 & 1 \\
Aeciospore & 24 & 27 & $1: 1$ & 0.088 & 0.767 & 1 \\
Urediniospore & 27 & 24 & $1: 1$ & 0.088 & 0.767 & 1 \\
Pooled & 51 & 51 & $1: 1$ & 0.0 & 0.999 & 1 \\
Homogeneity chi-square & & & 0.157 & 0.692 & 1 \\
\hline
\end{tabular}

Table 3. Contingency table comparing genotypic differences in resistance against artificial inoculation of 51 Ribes nigrum genotypes with aeciospores and urediniospores of Cronartium ribicola

\begin{tabular}{lcrcc}
\hline & & \multicolumn{3}{c}{ Aeciospore-treated $\mathbf{F}_{\mathbf{1}}$} \\
\cline { 3 - 5 } Contingency & & + & - & Total \\
\hline Urediniospore- & + & 22 & 5 & 27 \\
treated $F_{1}$ & - & 2 & 22 & 24 \\
& Total & 24 & 27 & 51 \\
\hline
\end{tabular}

Table 4. Two-way ANOVA displaying effects of genotype and spore type and their interaction on susceptibility of 51 Ribes nigrum $\mathrm{F}_{1}$ genotypes to aeciospores and urediniospores of Cronartium ribicola

\begin{tabular}{lrccrr}
\hline Source & df & SS & MS & $\boldsymbol{F}$ stat & $\boldsymbol{P}$ \\
\hline Genotype & 50 & 26.77 & 0.535 & 3.948 & $<0.001$ \\
Spore type & 1 & 0.152 & 0.152 & 1.119 & 0.291 \\
Genotype $\times$ Spore type & 50 & 7.981 & 0.159 & 1.219 & 0.164 \\
Residuals $^{\mathrm{a}}$ & 255 & 33.38 & 0.130 & & \\
\hline
\end{tabular}

a Both spore treatment were replicated 3 times. 
frame in which Ribes hosts are exposed to primary inoculum, in comparison to the limited dispersal distance and short period of urediniospore production in the mid- to late-summer.

Our result indicates that either spore type should work equally well as inoculum in resistance trials on $R$. nigrum. Aeciospores are easy to collect and can tolerate freezing during laboratory storage. Aeciospores are suggested as a first choice for Ribes inoculation tests. Uredinial fungal colonies, available in cultivated Ribes settings, should be gathered fresh and used directly, or maintained on young, vigorous plants. Artificial inoculation treatments with either aeciospores or urediniospores can determine Ribes resistance to WPBR.

\section{ACKNOWLEDGMENTS}

The authors thank Richard Sniezko, Paul Zambino, Brian Geils, and the staff of the DGRC and NCGR for spore collecting and inoculation assistance. The authors also thank Nahla Bassil and Everett Hansen for editorial suggestions on the manuscript. Special appreciation is given to the Northwest Center for Small Fruit Research and CRIS 5358-21000-038-00D for financial support for this research.

\section{LITERATURE CITED}

1. Brennan, R. M. 1996. Currants and gooseberries. Pages 191-295 in: Fruit Breeding, Vol. II:
Vines and Small Fruits. J. Janick and J. N. Moore, eds. John Wiley \& Sons, New York.

2. Burnes, T. A., Blanchette, R. A., Smith, J. A., and Luby, J. J. 2008. Black currant clonal identity and white pine blister rust resistance. HortScience 43:200-202.

3. Dale, A. 2000. Potential for Ribes cultivation in North America. HortTechnology 10(3):548554.

4. Dalton, D. T., and Hummer, K. E. 2009. Inheritance of the $C r$ gene in Ribes nigrum. J. Am. Pom. Soc. 63(4):142-144.

5. Hahn, G. G. 1948. Immunity of Canadian black currant selections from blister rust. Phytopathology 38:453-456.

6. Hahn, G. G. 1949. Evidence of the nonexistence of physiological races in Cronartium ribicola. Phytopathology 39:85-87.

7. Hummer, K. E. 1997. Diamonds in the rust: Ribes resistance to white pine blister rust. Fruit Varieties J. 51:112-117.

8. Hummer, K. E., and Finn, C. 1999. Third year update: Ribes susceptibility to white pine blister rust. Acta Hortic. 505:403-408.

9. Hummer, K., and Picton, D. D. 2002. Pine blister rust resistance screening in Ribes germplasm. Acta Hortic. 585(1):287-291.

10. Kaitera, J., and Nuorteva, H. 2006. Susceptibility of Ribes spp. to pine stem rusts in Finland. For. Pathol. 36:225-246.

11. Kinloch, B. B., Jr. 2003. White pine blister rust in North America: Past and prognosis. Phytopathology 93:1044-1047.

12. Kinloch, B. B., Jr., Sniezko, R. A., and Dupper, G. E. 2004. Virulence gene distribution and dynamics of the white pine blister rust pathogen in western North America. Phytopathology
94:751-758.

13. Maloy, O. C. 1997. White pine blister rust control in North America: A case history. Annu. Rev. Phytopathol. 35:87-109.

14. McDonald, G. I., Richardson, B. A., Zambino, P. J., Klopfenstein, N. B., and Kim, M.-S 2006. Pedicularis and Castilleja are natural hosts of Cronartium ribicola in North America: A first report. For. Patholy. 36:73-82.

15. Mielke, J. L. 1943. White pine blister rust in western North America. Yale University School of Forestry Bull. 52. New Haven, CT.

16. Richardson, B. A., Zambino, P. J., Klopfenstein, N. B., McDonald, G. I., and Carris, L. M. 2007. Assessing host specialization among aecial and telial hosts of the white pine blister rust fungus, Cronartium ribicola. Can. J. Bot. 85:299-306.

17. Strickberger, M. W. 1985. Genetics. 3rd ed. Macmillan Publishing Company, New York. pp. 126-146.

18. Van Arsdel, E. P., Conklin, D. A., Popp, J. B., and Geils, B. W. 1998. The distribution of white pine blister rust in the Sacramento Mountains of New Mexico. IUFRO Rusts of Forest Trees Working Party Conference, 1st. R. Jalkanen, P. E. Crane, J. A. Walla, and T. Aalto, eds. Finnish Forest Research Institute, Rovaniemi, Finland. Res. Pap. 712:275-283.

19. Zambino, P. J. 2000. Evaluating white pine blister rust resistance in Ribes after artificial inoculation. HortTechnology 10:544-545.

20. Zambino, P. J., Richardson, B. A., and McDonald, G. I. 2007. First report of the white pine blister rust fungus, Cronartium ribicola, on Pedicularis bracteosa. Plant Dis. 91:467. 